\title{
The Impact of Online Monolingual and Bilingual Dictionaries on Vocabulary Learning
}

\author{
Wijesuriya, K. \& Dissanayake, S. \\ keshani.w@sliit.lk,sucheru.d@sliit.lk \\ School of Natural Science, Faculty of Humanities and Sciences, SLIIT, Malabe, Sri Lanka
}

\begin{abstract}
The studies on the comparison of online monolingual dictionary (OMD) and online bilingual dictionary (OBD) for English on undergraduate level have not been carried out. The objective of this study is therefore to identify the impact of online monolingual and online bilingual dictionary use in vocabulary acquisition and retention among undergraduates. Forty Engineering undergraduates in their first term at CEFR (Common European Framework of Reference) B1 level in proficiency were selected after having a pretest and this sample of students knew none of the intended vocabulary to be tested. The students were randomly allocated into two groups: Online Monolingual Dictionary (OMD) and Online Bilingual Dictionary (OBD) groups. Both groups were exposed to an unknown set of ten academic words using an online monolingual dictionary and an online bilingual dictionary (English-Sinhala/ English-Tamil) respectively. They were instructed to find the meanings of the target words using the respective dictionary. The same vocabulary tests, immediate test and posttest were then administered in both groups to check the effectiveness of the treatments. While the results of these two tests demonstrated that both groups were able to acquire and retain vocabulary under each online dictionary use, the independent sample t-test confirmed that mean scores of the immediate test and posttest were significantly higher $(\mathrm{p}<0.05)$ in the OMD group than the corresponding values in the OBD group, irrespective of whether the variances between two groups were equal or not. The results confirmed that online monolingual dictionary use is significantly effective over online bilingual dictionary use in vocabulary acquisition and retention. Online monolingual dictionaries are thus recommended as a more successful tool to be used by English as a Second language (ESL) learners to improve vocabulary of the undergraduates.
\end{abstract}

Keywords: English as a Second Language, Online bilingual dictionary, Online monolingual dictionary, Vocabulary acquisition, Vocabulary retention 


\section{Introduction}

Dictionary use is considered a beneficial tool in the field of language learning and teaching in improving language competency. The reason is that dictionaries contain a myriad of information in terms of phonology, morphology, grammar, and semantics (ElSayed \& Siddiek, 2013; Hayati \& Fattahzadeh, 2006; Luppescu \& Day, 1993; Nation, 2001). Monolingual dictionaries in which the target words are defined in the same language, and bilingual dictionaries, in which the target words are defined in a second language, probably the first language of the user, are the two main categories that are currently popular among language learners and teachers. A third type, the bilingualized dictionary, has also been identified by researchers (Amirian \& Heshmatifar, 2013; Fageeh, 2014). For the present study, however, only the monolingual and bilingual dictionary types have been considered.

Knowledge of vocabulary is an integral part of the language competency of an individual. Knowing the right words to use is at the centre of having a meaningful and effective conversation (Chastain, 1998, as cited in Yazdi, 2014). Celce-Murcia (2001) further states that "vocabulary learning is central to language acquisition, whether the language is first, second, or foreign" (p.285). While other factors such as the socio-cultural context and use of syntax have a key influence on the effective use of language, it cannot be overlooked that vocabulary stands out as an indispensable element. It is highlighted by researchers that learners of English should have reached a threshold of 5000-8000 lexical items to achieve the status of independent learners, and that they require from 450,000 to 750,000 words if they are to develop reading comprehension and writing skills to perform better in their academic work (Coady, 1997; Stahl, 1999 and Tompkins, 2005, as cited in Fageeh, 2014). Accordingly, the study of methods that would assist the learner to acquire and retain vocabulary in the target language has become an important area in ESL and EFL (English as a Foreign Language) research.

Dictionary use and learning vocabulary are two closely interconnected areas. For instance, Schmitt (2002) identifies dictionary use as one of the four main strategies which help the identification and retention of the meaning of unknown words; the other three being guessing from contextual clues, deliberately studying words on word cards, and using word parts (as cited in Yazdi, 2014). Thus, it is pertinent to probe further into the contribution of different types of dictionaries in vocabulary acquisition and retention to employ the effective method in the ESL classroom.

\section{Monolingual and Bilingual Dictionary Use}

According to the proponents, monolingual dictionaries offer attention to high-frequency words and means to employ them, along with the definitions (Ali, 2012; Hayati \& Fattahzadeh, 2006; Yazdi, 2014). Encouraging learners to use this type of dictionary provides significant assistance in developing fluency as definitions are given in context. In contrast, bilingual dictionaries provide singleword translations which may not always demonstrate the application of the target word in the appropriate discourse (Hayati \& Fattahzadeh, 2006). Furthermore, research 
by $\mathrm{Ng}$ (2016) identified the positive influence of monolingual dictionaries on improving L2 lexical knowledge by eliminating L1 interference and otherwise. On the other hand, the same study has identified that while bilingual dictionaries were capable of lexical errors which were not influenced by the learners' L1, they aggravated the errors resulting from $\mathrm{L} 1$ influence.

Considering the bias towards the bilingual type, these dictionaries are preferred by learners as they provide the direct equivalent of a word from one language to another, which facilitates comprehension and saves time. Studies by Aust et al. (1993) and Hayati $\&$ Fattahzadeh (2006) highlight that there are no significant differences in comprehension and vocabulary test scores of monolingual and bilingual dictionary users, except that the monolingual dictionary users consume more time in completing tasks. The study by Hayati \& Fattahzadeh (2006) included undergraduates specializing in English, divided into two groups, required to read a text for meaning with the aid of a monolingual or bilingual dictionary. These participants were then exposed to an immediate vocabulary recall test, a delayed vocabulary recall test, and a vocabulary retention test that were administered after two and four weeks respectively from the immediate test. The results demonstrated that both groups had benefitted equally as only slight differences could be observed between the performances at the immediate and delayed vocabulary recall tests. Hence, the researchers recommend bilingual dictionaries for ESL/ EFL courses where the time constraint is high. However, Hayati \& Fattahzadeh's (2006) research also found that long term vocabulary retention was significantly higher with the users of monolingual dictionaries, as the level of decrease at the retention test was low for the participants who used the monolingual dictionary as opposed to the level of decrease manifest in the results of the same test conducted for bilingual dictionary users. This finding also conforms to previous research of Chastain (1988), which identifies a positive direct relationship between time and the level of retention: the longer the duration to search for vocabulary, the longer the retention level (as cited in Hayati \& Fattahzadeh, 2006). Monolingual dictionaries are thus recommended by these researchers to be more effective when a longer duration of time is available for the learners to use the dictionary.

\section{Online Dictionary Use}

The field of ESL teaching and learning has not been immune to the rapid advancements of digital technology; one result being the advent of electronic and online dictionaries. Studies by Koga (1995), Chen (2011), Mekheimer (2012) (as cited in Fageeh, 2014), and Amirian \& Heshmatifar (2013) and Wolter (2015) found electronic and online dictionary use to be more effective in vocabulary learning and retention over paper dictionaries.

Amirian and Heshmatifar (2013) examined the learning and long-term vocabulary retention of 60 high school lower-intermediate EFL learners. These students were divided into two groups and exposed to five sessions of vocabulary learning with one group instructed to use an electronic dictionary and the other, a paper dictionary. The immediate and delayed post-test results showed an overall higher 
performance rate by the group that used the electronic dictionary at all the sessions. The researchers thus argue that electronic dictionaries are advantageous over paper dictionaries in vocabulary gain and long-term retention. They further highlight features such as the ease and speed of using an electronic dictionary and the "multiplicity of information (translation, definition, examples, pictures, games)" provided by this type of dictionary as reasons for its success over the paper dictionary (Amirian and Heshmatifar, 2013, p. 42).

Considering the recent study by Wolter (2015), the preference for online and paper dictionary use was examined in relation to undergraduate ESL learners and English Language instructors. The findings highlighted that students felt more comfortable using online dictionaries to learn vocabulary and that they believed they had a better knowledge of how to use online dictionaries compared to printed dictionaries. The instructors too believed that students fare better with online dictionaries.

Studies such as the above, while demonstrating the effectiveness of online dictionaries over paper dictionaries, do not, however, compare the use of the online monolingual (English) and online bilingual (English and the user's L1) dictionary. On the whole, research studies on the use of these two categories of online dictionaries are less in comparison to the same based on conventional paper dictionaries (Fageeh, 2014).

Thus, the objective of the present study is to build upon previous research on dictionary use and to fill the gap related to studies comparing the effect of online monolingual and bilingual dictionary use on vocabulary learning and retention.

\section{Materials and Methods}

The participant group consisted of first term engineering undergraduates in a private university in Sri Lanka. This sample included male students at the B1 level of proficiency in English according to the Common European Framework of Reference. The ten target academic words tested in this study included isolated academic words. Participants were initially exposed to a pretest to form a homogeneous group in proficiency by giving a simple pre-test to verify their understanding of the meanings of the intended sample of words. Consequently, some students who knew at least one word among the target words were eliminated and 40 students who knew none of the intended vocabulary items were selected as the sample. Participants were informed of the purpose and their approval to participate in the study were obtained before the commencement. The participants in the sample were randomly divided into two groups of 20 participants: Online Monolingual Group and Online Bilingual Group. These two classes used online bilingual dictionaries and online monolingual dictionaries respectively. For referential purposes, classes will hereafter be introduced in the text as the Online Monolingual Dictionary (OMD) and Online Bilingual Dictionary (OBD) groups.

The participants in the OMD group used the Collins Online Dictionary. The OBD group consisted of students who used Tamil and Sinhala as their L1. Hence, students who used Sinhalese as their L1 used Madura Online Dictionary whereas Tamil students in the OBD 
group used the http://dictionary.tamilcube. com/ dictionary respectively. Data were collected through immediate tests and posttests held individually at different intervals in the learning process. Target academic words included ten words, comprising of nouns, verbs and adjectives: equilibrium, interlocking, pragmatic, stereotype, propagate, rudimentary, perpendicular, ensue, convene, superimpose. Under these differentiated learning strategies used, both the classes received the same testing materials during the immediate test and the post-test. Afterwards, students were given an immediate test which comprised of two tasks. One task was to match the underlined target word as they appear in a meaningful sentence to their definitions given below and the second task was to select the appropriate target word from a box to fill in the blanks in a meaningful sentence. Also, the posttest comprised of a task of substituting a bold word in a sentence using target words given in a box.

Participants were informed of the purpose of this study and agreed to participate. Students in the OBD group explored the meaning of the target words using a bilingual dictionary in their respective $\mathrm{L} 1$ whereas the OMD group explored the meaning of target words in L2.

Students were given a simple task of finding definitions of the target words in the worksheet from their respective dictionaries and producing them in the language as recorded in those dictionaries. The OMD group was constantly monitored during the learning process to avoid the use of the online bilingual dictionary and the OBD group was monitored to avoid the use of the online monolingual dictionary. An immediate test was administered thereafter to verify the immediate retention level in each class after being exposed to the respective dictionary use. The immediate test included matching underlined target words that appeared in meaningful sentences to their definitions given below and another exercise on using the target words given in a box appropriately to fill in the blanks in sentences. Each task was awarded a maximum mark of ten (10) with the total marks for both tasks being twenty (20).

Basic statistics for two groups were obtained separately. The test marks of the Bilingual class and the Monolingual class were compared through the independent sample t-test to assess whether there had been a statistically significant difference for both immediate test and post-test. The marks are varied between 0 and 10. Data were analyzed using SPSS.

\section{Results and Discussion \\ Results of the immediate test}

On the condition that awareness of the target words positioned at zero which was ascertained through the pre-test. The basic statistics are shown in Table 1.

\section{Table 1:}

Summary statistics of the immediate test

\begin{tabular}{lcc}
\hline Statistics & OMD Group & OBD Group \\
\hline Mean & 8.15 & 7.15 \\
\hline SD & 1.42 & 1.35 \\
\hline SE & 0.32 & 0.30 \\
\hline Minimum & 4 & 4.5 \\
\hline Maximum & 10 & 9 \\
\hline
\end{tabular}

$\mathrm{SD}=$ Standard Deviation, $\mathrm{SE}=$ Standard error 
Results in Table 1 indicates that the marks of the immediate test in the OBD group varied between 4.5 and 9 with a mean of 7.15 and SD of 1.35. The marks of the OMD group varied between 4.5 and 9 with the mean value of 8.15 and SD of 1.42. Furthermore, it can be seen that the two standard deviations were almost the same.

In order to test whether there was a significant difference of the mean marks of the immediate test between Online Bilingual Dictionary and the Online Monolingual Dictionary groups, an independent sample t-test was conducted. Under the assumption of equal variances between two groups, the observed test statistic was 2.28 and the corresponding $\mathrm{p}$ value was 0.014 . As the P-value (0.014) was less than $5 \%$, it can be concluded that the mean marks of the OMD group and OBD were significantly different. As there were only two groups, it was obvious that mean marks of the OMD group was significantly higher than that of the OBD group in the immediate test.

Furthermore, it was found that the mean of the OMD group at the immediate test was significantly higher than that of OBD group even when the variances are not equal. Therefore, it implied that mean marks of OMD was significantly higher than the mean marks of OBD irrespective of the fact whether the variances are equal or not. Therefore, it can be recommended that OMD is more superior to OBD in improving vocabulary knowledge of the undergraduates

\section{Test results of the post-test}

The basic statistics of the post-test between two groups are shown in Table 2.

\section{Table 2:}

Basic statistics of the post-test

\begin{tabular}{lcc}
\hline Statistics & OMD Group & OBD Group \\
\hline Mean & 7.8 & 6.7 \\
\hline SD & 1.68 & 1.45 \\
\hline SE & 0.38 & 0.33 \\
\hline Minimum & 4 & 4 \\
\hline maximum & 10 & 10 \\
\hline
\end{tabular}

The marks of post-test of OMD group varied between 4 and 10 with a mean and sd of 7.8 and 1.68 respectively. Similarly, the marks of the post-test in the OBD group also varied between 4 and 10 with a mean and SD of 6.7 and 1.45 respectively. As explained in the aforementioned immediate test, it was found that the mean marks of post-test between OMD group and OBD group were significantly different (t-test statistic $=2.22$ and $p=0.016$ ) irrespective of the fact whether the variances were equal or not.

Therefore, the mean value of the Online Monolingual Dictionary group was significantly higher than that of the Online Bilingual Dictionary group. Accordingly, vocabulary internalization through online monolingual dictionaries and online bilingual dictionaries, irrespective of their differences, have contributed to incidental vocabulary acquisition. On the condition that the awareness on target words positioned at zero in both classes before the treatment, 
the OMD group acquired approximately 8 words whereas the OBD group acquired approximately 7 words at the immediate test. At the posttest, the monolingual class has approximately acquired and retained 8 words whereas the bilingual class has approximately acquired and retained 7 words.

The application of the independent sample t-test confirmed that the numerical difference was significantly higher both at the immediate test and the posttest among Online Monolingual Dictionary users. Also, this observation was found to be valid in both tests regarding the means of the OMD group irrespective of whether the variances were equal or not.

Thus, the participants of the OMD group have effectively internalized the target vocabulary over those in the OBD group at the immediate exposure. Furthermore, the posttests administered after a week have confirmed that the use of an Online Monolingual Dictionary positively affected long-term vocabulary internalization over the use of an Online Bilingual Dictionary.

At the theoretical level, the aforesaid finding conforms to the study of Hayati \& Fattahzadeh (2006) which identifies that long-term vocabulary retention was significantly higher with the users of monolingual dictionaries.

The advantage of monolingual dictionaries over bilingual dictionaries could be attributed to several reasons. According to Laufer and Aviad (2006), students generally acknowledge the effectiveness of monolingual dictionaries over bilingual dictionaries, a factor that was long established by lexicographers and language teachers. Scholfield (2012) claims that the use of bilingual or semi-bilingual dictionaries are likely to demotivate second language learners of English when they rely on translations in L1. Thus, the requirement of habit formation in the target language is likely to be disrupted.

Moreover, Nation (1990) advocates the use of monolingual dictionaries as Bilingual dictionaries offer translation instead of a definition, which disturbs the development of paraphrasing skills to prepare the learner for difficult vocabulary that they might encounter in future.

\section{Acknowledgement}

We acknowledge the contribution of all the students who consented and participated in the study. We would also like to show our deep appreciation to Dr Manouri Jayasinghe for her encouragement and leadership in driving us towards our professional goals. Finally, all the colleagues at SLIIT, Malabe and our family members who supported us in this joint venture are remembered with gratitude.

\section{References}

Ali, D.H. I. H. (2012). Monolingual dictionary use in an EFL context. English Language Teaching 5 (7). http://dx.doi. org/10.5539/elt.v5n7p2.

Amirian, S. M. R., \& Heshmatifar, Z. (2013). The impact of using electronic dictionary on vocabulary learning and retention of Iranian EFL learners. International Journal of Research Studies in Educational Technology, 2(1), 35-44. http://consortiacademia. org/wp-content/uploads/IJRSET/ IJRSET_v2i1/384-1375-1-PB.pdf. 
Aust, R., Kelley, M. J., \& Roby, W. (1993). The use of hyper-reference and conventional dictionaries. Educational Technology Research and Development 41 (4), 63-73. https://doi.org/10.1007/ BF02297512.

Coady J. (1997). L2 vocabulary through extensive reading. In J. Coady \& A. Huckin (Eds.), Second-language vocabulary acquisition: A rationale for pedagogy (pp. 225-237). Cambridge, England: Cambridge University Press.

Celce-Marcia, M. (2001). Teaching English as a second or foreign language (3rd ed.). Boston Massachusetts: Heinel \& Heinel, 275.

El-Sayed, A., \& Siddiek, A. (2013). Monolingual and bilingual dictionaries as effective tools of the management of English language education. Theory and Practice in Language Studies, 3(10), 1744-1755. http://www. academypublication.com/issues/past/ tpls/vol03/10/04.pdf.

Fageeh, A. I. (2014). Effects of using the online dictionary for etymological analysis on vocabulary development in EFL college students. Theory and Practice in Language Studies, 4(5), 883-890. http://www.academypublication.com/ issues/past/tpls/vol04/05/04.pdf.

Hayati, M. \& Fattahzadeh,A.(2006). The effect of monolingual and bilingual dictionaries on vocabulary recall and retention of EFL learners. Journal of the Reading Matrix, 6(2), 125-134. ttp://citeseerx.ist.psu.edu/viewdoc/download?doi $=10.1 .1 .125 .1199 \&$ rep $=$ rep $1 \&-$ type $=$ pdf.

Laufer, B., \& Aviad, T.L. (2006). Examining the effectiveness of bilingual dictionary plus- a dictionary for production in a foreign language. International Journal of Lexicography, 19(2), 135-155.
Luppescu, S., \& Day, R. (1993). Reading, dictionaries, and vocabulary learning. Language Learning 43(2), 263-287. http://dx.doi. org/10.1111/j.1467-1770.1992. tb00717.x.

Nation, I.S.P. (1990). Teaching and learning vocabulary. New York: Newbury House Publishers.

Nation, I.S.P. (2001). Learning vocabulary in another language. Cambridge University Press.

Ng, C.W. (2016). Impacts of the monolingual and bilingual dictionaries on the lexical errors committed by EFL learners in Hong Kong: A semantic analysis. Lexicography ASIALEX 2, 143-173. https://doi.org/10.1007/s40607-0160024-0.

Scholfield, P. (2012) Why shouldn't Monolingual Dictionary be as easy to use as Bilingual or Semi-bilingual ones? Retrieved September 2012 from http://www.etni.org/monodict.html.

Wolter, L. A. (2015). Dictionary use and preferences of L2 English learners in an intensive English context [Master's thesis, St. Cloud State University]. Culminating Projects in English. https://repository.stcloudstate.edu/ engl_etds $/ 14$.

Yazdi, S. S. H. (2014). Iranian EFL learners' perceptions about monolingual dictionaries and their vocabulary proficiency. Procedia - Social and Behavioral Sciences 98, 631 - 636. https://cyberleninka.org/ article/n/1004818. 